\title{
NAS PUBLICAÇÕES SOBRE LIVROS DE LEITURA NO INÍCIO DO SÉCULO XX: TRAÇOS DE UMA CULTURA MATERIAL ESCOLAR
}

DOI: http://dx.doi.org/10.1590/2236-3459/55270

\author{
Ilsa do Carmo Vieira Goulart \\ Universidade Federal de Lavras, Brasil.
}

$\cos 80$

\begin{abstract}
Resumo
O texto objetiva apresentar quais representações a respeito de livros de leitura se fizeram presentes em algumas publicações impressas, no período entre 1927 a 1946, como também destacar as possibilidades da influência destas ideias nas práticas de leitura nas escolas públicas paulistas. Parte-se da premissa de que o livro pode ser considerado um objeto concreto de uma "cultura material escolar", por encontrar-se ali um espaço, uma temporalidade e uma linguagem. A análise indica que os enunciados se mostraram direcionados, a princípio, à legitimação de interesses políticos para se implementar um ensino nacionalizado e uniformizado, ao estabelecerem critérios de configuração de uma obra didática de qualidade para, em seguida, voltarem-se aos leitores alunos e professores.

Palavras-chave: livros de leitura, representações de leitura, cultura material escolar.
\end{abstract}

\section{THE PUBLICATIONS ABOUT READING BOOKS IN THE EARLY 20TH CENTURY: TRACES OF A SCHOLAR WRITTEN CULTURE}

\begin{abstract}
The text aims to present which representations about reading books were present in some print publications, in the period among 1927 to 1946 , as well as highlight the possibilities of influence of these ideas in the reading proceeding practices in public schools of São Paulo state. It begins from the premise that book can be considered a concrete object of a scholar written culture, due to find there a space, a temporality and a language. The analysis indicates that the written statements proved directed, in principle, to the establishment and legitimation of political interests to implement a nationalized and uniform teaching, since it establishes elaboration criteria of a qualified didactic work, then, it is directed to the students and teachers readers.

Keywords: reading books, representations of reading, scholar school culture.
\end{abstract}




\title{
EN LAS PUBLICACIONES SOBRE LOS LIBROS DE LECTURA EN EL SIGLO XX: VESTIGIOS DE UNA CULTURA MATERIAL ESCOLAR
}

\section{Resumen}

El texto tiene como objetivo presentar qué representaciones sobre la lectura de los libros estaban presentes en algunas publicaciones impresas en el período de 1927 a 1946, así como resaltar las posibilidades de influencia de estas ideas en la realización práctica de la lectura en las escuelas públicas en el estado de São Paulo. Es la premisa de que el libro puede ser considerado un objeto concreto de escolares de cultura, para encontrar un espacio, una temporalidad y un lenguaje. El análisis indica que las declaraciones estaban destinadas, en primer lugar, la legitimación de los intereses políticos para implementar una educación nacionalizada y uniforme, Al establecer criterios de configuración de un trabajo de calidad de la enseñanza, luego volver a los estudiantes y los lectores de la Facultad.

Palabras clave: libros de lectura, representaciones de la lectura, cultura material escolar.

\section{PUBLICATIONS SOR LES LIVRES DE LECTURE AU DÉBUT DU XXE SIÈCLE: TRACES D'UNE CULTURE DES FOURNITURES SCOLAIRES}

\begin{abstract}
Résumé
Le texte vise à présenter les représentations sur la lecture de livres étaient présentes dans certaines publications, dans la période de 1927 a 1946, ainsi que de mettre en évidence les possibilités d'influence de ces idées dans les pratiques de la performance de lecture dans les écoles publiques d'état São Paulo. C'est la prémisse que le livre peut être considéré comme un objet concret d'une culture des fournitures scolaires, pour trouver un espace, une temporalité et une langue. L'analyse indique que les déclarations avaient pour but, dans un premier temps, la légitimation des intérêts politiques à mettre en œuvre une éducation nationalisée et uniforme, Lorsque vous définissez des critères de configuration d'un travail de qualité de son enseignement, puis revenir aux étudiants et aux lecteurs de la faculté.

Mots-clés: livres de lecture, représentations culturelles des fournitures scolaires.
\end{abstract}




\section{Considerações iniciais}

L ste trabalho parte da premissa de que os discursos escritos publicados nos periódicos e documentos oficiais, no início do século XX, apresentamse carregados de sentido e de intencionalidade, mesmo que se tratem de escritos produzidos em outros tempos e lugares, os textos trazem demarcações de uma articulação de ideias e de representações a respeito daquilo que se fala, isto porque a palavra, conforme Bakhtin (2006) acompanha, explana e articula um ato ideológico.

Frente a alguns textos, selecionados por trazerem a temática da leitura, de dois periódicos e duas obras, a saber, a Revista Escolar (1927), o Programa de Linguagem (1934), a Revista de Educação (1933, 1934) e a Escola Moderna (1946), este estudo toma como base a concepção de apropriação cultural como invenção criadora no processo de produção de uma obra didática. Deste modo, questiona o que e de que forma os discursos construídos no início do século XX, sobre os livros de leitura, poderiam revelar em relação ao ideário de leitura e dos procedimentos metodológicos que envolviam a utilização e a apropriação das obras nas escolas públicas paulistas. Até que ponto é possível compreender o que tais escritos traziam como marcas de uma representatividade, a respeito do que se entendia por "bom" livro de leitura?

Para tanto, a pesquisa se apoia na perspectiva teórica e metodológica da história cultural que, de acordo com Chartier (2009, p. 47), tem como um dos principais desafios "pensar a articulação entre o discurso e as práticas". Ao refletir sobre essa questão, adota-se a forma do "giro linguístico", que segundo o autor, se baseia em duas ideias fundamentais: uma de que "[...] a língua é um sistema de signos, cujas relações produzem significados múltiplos e instáveis", e a outra de que "[...] a realidade não é uma referência objetiva externa ao discurso", mas é sempre construída de e na linguagem. Toda prática se situa, se constitui na ordem do discurso, o que se aproxima da teoria da enunciação de Bakhtin $(2006,2003)$, que a palavra se dirige a interlocutor, constitui-se e move-se ante a um "horizonte social".

Para Chartier (2009) o objeto principal de uma história que se propõe a conhecer, a forma pela qual os sujeitos dão sentido às práticas e a seus enunciados, encontra-se na tensão entre a capacidade inventiva dos indivíduos (ou comunidades) e a restrição e a limitação das posições de dominação do que se pode dizer, pensar e fazer.

É nesse contexto que Chartier $(2009,2002,1996,1994)$ apresenta o conceito de "representação", que se torna uma ideia determinante da história cultural, permitindo vincular as posições e as relações sociais com a maneira como os indivíduos ou grupos se percebem e percebem o que os envolve.

Chartier (2002) mostra que as representações não ocupam um status entre ser, ou não, imagens verdadeiras ou falsas de uma realidade externa, mas possuem uma força própria que conduz à crença de uma realidade externa a partir daquilo que acredita que é. A representação pode ser vista como uma produção que rompe com a sociedade e se incorpora no indivíduo.

Outra concepção volta-se para a ideia da cultura material escolar, que segundo Vidal $(2009,2005)$, abrange todos os materiais e produtos do escrever, os quais ocupam uma posição expressiva no conjunto das práticas escolares e administrativas da escola e "[...] tomados em sua materialidade, os objetos da escrita permitem não apenas a 
percepção dos conteúdos ensinados, mas o entendimento do conjunto de afazeres ativados no interior da escola" (VIDAL, 2009, p. 31).

Nesta perspectiva, o trabalho salienta a importância de identificar a maneira como os discursos sobre tais práticas se constroem em cada momento histórico, pois conforme descreve Chartier (2009, p. 42), seja

[...] nas e pelas obras, ou ao menos algumas delas que se apoderam dos objetos e das práticas da cultura escrita de seu tempo para transformá-las em recursos estéticos movidos por fins poéticos, dramáticos ou narrativos. Os processos que se conferem existência ao escrito em suas diversas formas, públicas ou privadas, efêmeras ou duradouras, também se convertem no próprio material da invenção literária.

Produzidas em uma ordem específica, as obras fogem delas e adquirem existência ao receber as significações que seus diferentes públicos Ihes atribuem, às vezes em muito longa duração.

A pesquisa não pretende analisar a maneira como os livros de leitura eram apropriados ou as diferentes formas de uso deste material, mas intenta apresentar como os discursos sobre a prática de leitura eram organizados, postos em circulação e discussão e de que forma esse discurso estava relacionado ou até que ponto era fator determinante na configuração dos livros de leitura, legitimando a qualidade da obra.

Tendo em vista que o livro pode ser considerado um objeto concreto de uma cultura material escolar, por encontrar-se, ali, um espaço, uma temporalidade e uma linguagem, a pesquisa volta-se para a estruturação dos enunciados sobre a prática de leitura, procurando entender o que se diz, como se diz, sobre e para quem se diz.

Neste viés de discussão, seleciona para análise quatro textos publicados entre 1927 a 1946, elegidos por discorrerem, especificamente, sobre os modos de produção da linguagem escrita dos livros de leitura. São eles: o artigo publicado na Revista Escolar, de Emerson White, em 1927, intitulado "Preparação do mestre: o mestre - uso do livro de leitura"; o documento publicado em 1934, pelo Departamento de Educação do Rio de janeiro, intitulado "Programa de Linguagem"; o artigo de Marjory Hardy, "A leitura de livros no Primeiro Grau", publicado pela Revista de Educação (SP) em 1933 e o artigo de José Calvo, "O livro de texto", publicado em 1934 pela Revista de Educação (SP).

\section{A adesão ao livro escolar marcada por questões políticas, sociais e culturais}

O movimento político em busca da universalização do ensino, fez com que a educação brasileira, no período entre 1920 a 1940, passasse por várias reformas na instrução pública. Depois da reforma de Sampaio Doria1, em 1920, ocorreu a reforma da instrução pública implementada por Fernando de Azevedo², em 1927, no Distrito Federal,

\footnotetext{
1 Durante o Governo de Washington Luís, convida-se para a direção geral da Instrução Pública do Estado de São Paulo, em abril de 1920, o professor Sampaio Dória, que passa a elaborar a reforma do ensino, a qual se efetivaria na lei no 1.750 . De acordo com Cavaliere (2003), Sampaio Dória "representava à época a corrente liberal, a qual defendia a igualdade de oportunidades e a evolução pela educação. Era vinculado à Liga Nacionalista de São Paulo e via o analfabetismo como incompatível com a civilização". (CAVALIERE, 2003, p. 32). Para maior aprofundamento pode-se conferir, também, a pesquisa de Antunha (1967).

2 De acordo com Vidal (1994), Fernando de Azevedo foi nomeado Diretor Geral da Instrução Publica do Distrito Federal em 1927. Assessorado por uma comissão de educadores elaborou a reforma da educação que foi promulgada em janeiro do ano seguinte.
} 
um reposicionamento em relação à questão da inserção e da utilização do livro didático, principalmente em relação ao livro de leitura nas escolas públicas. Procurou-se, contudo, um esclarecimento de que o livro didático na Escola Nova não era visto como um elemento desprezível, mas procurou-se atribuir-lhe uma nova função inserida ao trabalho pedagógico do professor, especificamente relacionado ao ensino da leitura e escrita.

A ideia a respeito do livro didático passaria de um objeto centralizador das práticas pedagógicas de leitura, para um "instrumento de trabalho" na realização das atividades de leitura e escrita em sala de aula. De um elemento padrão de ensino, que trazia em si a função controladora e autoritária para assumir a condição de um "elemento de cultura", como descreve Azevedo (1933, p. 240):

$\mathrm{Na}$ Escola Moderna, a literatura escolar, embora em formação, assumia uma posição de relevância por permitir uma experiência humana com o conhecimento, possibilitando a fixação de aspectos reais da vida, por meio de uma experiência sensível, fosse pela página ou linha, pela cor, pelas formas, pelo relevo, pelo cheiro, pela palavra impressa ou imagem, o livro trazia aspectos tipográficos, concretos, que iriam despertar a sensibilidade, desenvolver o pensamento e a reflexão.

A aprendizagem por meio dos livros remetia a ideia de um ensino que tinha por base que a informação não se opunha ao ideário da Escola Nova, ao defender um ensino prático e moderno, mas para os reformadores da educação,

Ao contrario: o livro é precioso auxiliar da escola moderna; o livro continua a ter na escola o papel importante que sempre teve. A diferença a esse respeito está, não em sua abolição, que seria absurdo, mas sim na forma de utilizá-lo.

O livro continua a ser, como foi, repositório de saber; mestre e amigo sempre disposto a transmitir as informações que encerra, a comunicar a todos o que alguns descobriram, inventaram, compilaram ou organizaram. É, pois, para o ensino, auxiliar precioso que não poderia ser desprezado. (CAMPOS, 1946, p. 242)

A representação de uma ideia de que o livro como objeto auxiliar ao ensino, como um artefato que emite o saber e o conhecimento parece propagada nas páginas da obra Escola Moderna, o que revela uma "realidade ideológica", conforme descreve Bakhtin (2006, p. 67), a respeito do que se compreendia pelo uso ou não deste material nas escolas públicas.

Num momento em que se preconizava uma educação por intermédio da experiência, da observação, da "intuição", parecia que o livro didático não se instituiria um meio favorável à aprendizagem, porque a informação deveria vir acompanhada da reflexão e da experiência sensível. Com isso a aceitação do livro didático na realidade do ensino, moveu-se a partir da elaboração de discursos para se divulgar quais as melhores condições e formas de manejo do livro que iriam atribuir-lhe finalidades educativas, capaz de produzir a "chama do saber".

\section{O livro de leitura como instrumento básico para o trabalho do professor}

Embora se reconhecesse a importância do livro didático para o ensino, a ideia de "instrumento de trabalho" apareceu correlacionada ao trabalho docente, sua definição se mostrou resumida em "auxiliar precioso", o que favoreceu um discurso sobre o livro de 
leitura, a partir das reflexões das práticas e modos de seu uso. $O$ artigo publicado na secção Questões Gerais da Revista Escolar, de autoria do professor americano Emerson White, em 1927, intitulado "Preparação do mestre: o mestre - uso do livro de leitura", ao se falar de método de ensino, pressupunha que a presença habilidosa e bem formada do professor, seria "o elemento capital do ensino" e a "alma dos methodos".

Os discursos sobre o livro didático relacionavam-no às questões metodológicas, destacando que somente ao "mestre" competia as atribuições de selecionar de maneira inteligente o conhecimento, de ordenar e de coordenar os passos dos conteúdos a serem aprendidos, principalmente, em relação à leitura, pois "[...] as meras lições de leitura podem ser dirigidas por um espirito laborioso, que as tornará amenas, mas um systema de ensino cujo fim principal é o desenvolvimento e a educação do cérebro e do coração, requer a introspecção, a invenção, a habilidade, a inspiração dum mestre na arte de ensinar" (WHITE, 1927, p. 3).

Para White (1927), o professor deveria estar diante da classe preparado para as exigências que esta arte de ensinar iria lhe requerer, para isso deveria ter o conhecimento do livro, um domínio do assunto e dedicar-se ao preparo das disciplinas diariamente. $\mathrm{O}$ livro deveria ser apenas um auxiliar, pois o assunto necessitaria estar no "espírito":

Quando os alumnos usam o livro de leitura como instrumento básico de seu estudo, o professor deve se tornar tão familiar com esse livro, quanto ele deseja que os discípulos se tornem; do contrario, elle será incapaz de dar judiciosamente a necessária instrucção, assignalar as lições ou verificar o resultado do estudo. Finalmente, elle precisa não sómente conhecer o assumpto do livro, como a ordem em que é apresentado. Isto não significa que o mestre siga servilmente essa ordem e ou que mantenha o discípulo sob domínio de todos os factos apresentados. As lições serão assignaladas para aliviar o discípulo do estudo de questões sem importância que trazem muitos livros de leitura. (WHITE, 1927, p. 5)

O conteúdo do livro deveria ser, de acordo com White (1927), tão familiar para o professor que nem mesmo haveria a necessidade de empregá-lo no ensino das lições, com exceção no ensino da leitura, soletração, exercícios em que se precisasse do uso do texto:

Há poucas coisas tão perniciosas como o emprego servil do livro no ensino das crianças. Isto reduz o mestre a uma machina, coloca uma barreira entre ele e o alumno, reprime o enthusiasmo e torna a lição mecânica, sem vida. Depender do texto para corrigir as respostas do discípulo, é uma prova evidente de grande incompetência. O mínimo emprego do livro pelo mestre é o máximo do seu sucesso. O professor deve entrar em classe com o espirito cheio, a mão livre e um olhar também livre. (WHITE, 1927, p. 5)

Em meio às discussões que circundavam a implantação das inovações ideológicas da Escola Nova, os discursos sobre o livro didático alteravam-se, deslocavamse de uma preocupação a respeito dos modos de constituição da obra, para os modos de sua utilização no estabelecimento escolar. Os enunciados direcionavam-se para as diferentes possibilidades de uso deste instrumento no processo de ensino, da inserção deste material nas escolas e da sua adequação ao trabalho docente.

Os discursos deslocavam-se de eixos de significação, a princípio, da obra, envolvendo os aspectos pertencentes à elaboração, para em seguida remeter-se às práticas de ensino, visto que, agora, conforme artigo "O que quer a Escola Nova", 
publicado na Revista Escolar em 1927, o educador deveria conduzir progressivamente o "mecanismo psychico da criança", assim

Nas classes de ensino primário, as aulas devem ter uma feição compatível com a natureza do alumno; ellas devem constituir verdadeiras palestras nas quaes todos os alumnos possam colaborar sob a direção e orientação do mestre. Este, por sua vez, encaminhará as lições de maneira a tornal-as atraentes, dando aos seus discípulos a liberdade de interrogar e objectar, para o que os educará de fórma que a atividade de cada um manifeste em prejuízo da ordem e disciplina escolar. $(\mathrm{s} / \mathrm{n}, 1927, \mathrm{~s} / \mathrm{p})$

A proposta da Escola Nova era formar o mestre, segundo esse artigo da Revista Escolar, conscientizando-o dos seus deveres e das prioridades, longe dos preconceitos e dos processos mecânicos de aprendizagem, preparando-o como um homem completo, o que não significaria perfeito, mas uma pessoa que, de acordo com suas capacidades, tendesse a buscar o seu valor, entendendo-se

Como guia, pae, amigo e companheiro, agindo, portanto, com o coração e com a intellegencia, a acção do mestre não póde se restringir ao exclusivo 'officio' de ministrar letras e de alfabetizar puramente; vae além, duma constante preocupação de erguer o valor econômico e social dos indivíduos. Educar - urge repetir - não é apassivar a crianças aos conhecimentos e ás noções dos compêndios, erro a que, ainda, por falta de preparação adequada, insistem os que aferram á rotina ou aos processos da escola antiga e tradicional. A educação, pelo contrario, visa exercitar a atividade e a liberdade do alumno, espontaneamente, tornando-o uma força activa, digamos melhor, um fator positivo de progresso e de elevação moral da sociedade em que vivemos. (s/n, 1927, s/p)

Para Bittencourt (1993), este período de formação da literatura didática no Brasil, o professor assumia a posição de intermediário entre a obra didática e o aluno, sob a crença de que o saber escolar não se atingia diretamente, pois necessitava percorrer um trajeto entre a autoridade docente, sua capacidade de articulação e de exposição deste conhecimento, entretanto

O livro didático independente da condição do professor, no transcorrer do séc. XX, transformou-se em uma ferramenta de trabalho indispensável na sala de aula. $O$ aperfeiçoamento técnico na fabricação do livro e a possibilidade de ser consumido por um número cada vez maior de alunos aliados à comunidade de uma precária formação do corpo docente fizeram do livro didático um dos símbolos da cultura escolar, um depositário privilegiado do saber a ser ensinado. (BITTENCOURT, 1993, p. 283)

Este movimento de construção e consolidação da ideia do livro didático como um símbolo da cultura escolar, como "[...] um depositário privilegiado do saber a ser ensinado" ocorreu, segundo Bittencourt (1993), a partir da contribuição de três fatores: o primeiro referia-se ao aperfeiçoamento técnico da produção de obras didáticas; segundo ao número cada vez maior de alunos que adquiriam o direito ao acesso e a viabilidade de compra e o terceiro abrangia a ideia de formação do corpo docente, do livro como complementariedade do trabalho pedagógico.

Ao tratar sobre o uso dos livros de leitura nas escolas, os olhares inclinavam-se tanto para os professores, vistos como aqueles que facilitariam o domínio da habilidade de ler, quanto para a adequação de um espaço para a biblioteca escolar, que ganhava 
uma preocupação especial, por ser compreendida como um local apropriado para se promover a leitura.

\title{
O livro de leitura em discussão: definindo características para sua composição
}

O documento publicado em 1934, pelo Departamento de Educação, intitulado Programa de Linguagem, trouxe diferentes questões que envolviam a temática dos livros de leitura, no início do século XX, entre elas o espaço físico em que a leitura ocorria. Ao tratar da questão da instituição das "Bibliothecas" nas escolas, por exemplo, descreveu a existência de três lugares distintos e propícios para se utilizar a leitura dos "livros de leitura", que seriam: a biblioteca, a sala de aula e a casa do aluno.

Em casa, a finalidade do livro seria de incrementar o gosto pela ação de ler, distante do professor, longe da orientação e de uma metodologia, os livros indicados deveriam ser de preferência os de literatura. Já, a utilização dos livros, em sala de aula, assumia outra conotação, pois ali se necessitaria da presença e da atuação do professor: "[...] os livros vêm á classe para servir ás lições de momento, para exemplificações e citações que o professor queira fazer, para leitura coletiva, etc." (s/n, 1934, p. 96).

A biblioteca, diferentemente, era compreendida como um espaço em que a leitura envolvia tanto por uma atividade orientada e conduzida pelo professor, como também, uma atividade de leitura que poderia acontecer de forma independente, como um ato de silencioso, de maneira individualizada e interiorizada, pois

\begin{abstract}
A biblioteca é o lugar de ordem, de calma, de recolhimento e de beleza. A escola é quasi um santuário onde o espirito repousa, entre emoções estheticas de suavidade. Seu simples aspecto é o ensinamento e, pois, incitamento á ordem á calma necessária, á expansão e aperfeiçoamento da intelectualidade. Ambiente agradável, de ordem sem vetustez, de alegria sem ruído, de atividade sem balburdia, ambiente disciplinador e educativo por excellencia. (s/n, 1934, p. 97)
\end{abstract}

O Programa de Linguagem (1934) entendia que a escolha das obras que iriam compor o acervo da biblioteca merecia grande consideração. Desta forma, o documento apresentou uma classificação dos livros didáticos em duas grandes categorias: uma que correspondia aos de "informação ou didacticos" e outra aos de "literatura".

Os livros de "informação ou didacticos" referiam-se a todas as obras que pudessem ser utilizadas para ministrar noções, auxiliar 0 trabalho docente, a complementar as orientações dos professores e das observações dos alunos. Neste grupo foram colocados os livros de geografia, história, aritmética, álbuns diversos, revistas científicas.

Os livros de "literatura" receberam uma subdivisão: a) obras que despertavam "o gosto pela leitura", que correspondiam aos livros de estampas, álbuns, livros de histórias, folhetos diversos com figuras, etc.; b) obras que eram utilizadas para aprendizagem e cultivo da leitura, diziam respeito aos livros de leitura, livros de histórias, de contos, seletas, romances e, também, revistas e jornais.

Os livros de leitura foram colocados numa categoria de livros de "literatura", tanto pela sua constituição física, por apresentarem textos e imagens, quanto por serem compreendidos pela atividade a que remetiam, pelo uso a que eram indicados: uma 
leitura deleite, tais observações apareceram descritas detalhadamente pelo Programa de Linguagem:

\begin{abstract}
Os livros de leitura recreativa, ou de literatura, devem ser agradáveis e interessantes, moraes sem preocupação ostensiva de prégar a moral, de fórma literária o mais perfeita e mais bella possivel, de acordo com o grau de mentalidade das crianças a que se destinem. As figuras, de preferencia coloridas, devem ser cheias de vida, reaes, bem desenhadas; são indispensáveis nos livros destinados aos primeiros anos e serão mesmo quase exclusivamente de figuras os que sirvam para alumnos que ainda não saibam ler. $O$ assumpto deve ser: contos de fada, modernos e tradicionais, contos históricos, historias humorísticas, enigmas, historias de animaes e fabulas, poesias, etc.

Entre os livros dessa especie podem figurar para o $1 .$. anno: livros de figuras, com pequenos trechos de prosa ou verso (cantigas populares, quadrilhas, etc.), livros de historia, folhetos diversos, cartilhas de hygiene e outras desse gênero. Do 2.으 anno em diante os livros serão francamente de leitura e progressivamente mais difíceis, aproximando-se gradualmente dos typos de literatura para adultos. (s/n, 1934, p. 100)
\end{abstract}

A qualidade da materialidade do livro foi pontuada pelo Programa de Linguagem, ao estabelecer que a obra didática deveria trazer o conteúdo exposto com clareza, contendo uma metodologia agradável e interessante, escrito com linguagem simples e correta. A composição física do livro deveria ser de ótima "feitura material", não desmerecendo as dificuldades que isso acarretaria em termos econômicos, dever-se-ia contentar em apresentar uma boa impressão tipográfica, sem erros e com uma escrita nítida, para isso papel não poderia ser transparente, nem as linhas poderiam estar muito próximas, precisaria usar o "typo graúdo" para as "classes inferiores" e, gradativamente, ir diminuindo a fonte, até o tamanho normal, sem chegar nunca a utilizar letras "miúdas" (s/n, 1934, p. 100).

Campos (1946), ao descrever os modos de uso dos livros, na obra Escola Moderna, também recorreu a iniciativa de classificar as obras escolares. A autora utilizou a mesma denominação empregada na classificação dos livros, pelo Programa de Linguagem e, de maneira similar, dividiu-os em dois grandes grupos. Entretanto o trabalho de categorização distinguia-se pela ideia construída ou pelo o que a autora compreendia a respeito de livros "Didáticos", que para ela se referiam aos "livros de texto", ou de estudo de maneira geral e o restante das obras, que não se direcionam ao estudo, seriam os de "Literatura".

A designação de "Didáticos" foi atribuída às obras consideradas como meio auxiliares para a concretização do ensino, se referiam aos materiais os quais o professor recorria, todas às vezes, em que se percebesse impossibilitado de oportunizar uma observação direta da realidade. Vários materiais poderiam ser considerados "didáticos", por proporcionarem e auxiliarem na observação direta de uma informação, como os mapas, por exemplo, vistos como fontes de informação para se consultar. Entretanto, a autora defendia que um trabalho bem direcionado com os livros didáticos, organizado de maneira inteligente pelo professor, traria consideráveis vantagens para a aprendizagem e o cultivo da mentalidade do aluno.

A classificação dos livros didáticos atribuída pelo Programa de Linguagem de "Literatura" aos "Livros de texto", distanciava-se da compreensão que Campos (1946) apresentava tanto de "Literatura" quanto de "Livro de textos". Pois a denominação feita 
pela autora de "Didáticos" aos "Livros de texto" ocorreu por trazerem em sua concepção uma finalidade mais específica em relação ao ensino da língua e ao ensino da moral. Para ela, a preocupação com a moral deveria estar diluída na narrativa, de modo que a reflexão sobre a moralidade ocorresse a partir do enredo, garantindo o interesse pela história e a formação do caráter da criança.

Sob a delimitação da nova roupagem de "Didático", o "Livro de texto" ganharia olhares ainda mais minuciosos e preocupações mais direcionadas para quais práticas pedagógicas de leitura eram construídas com e sobre esse livro.

\section{O livro de leitura na escola: no delinear de modos de uso}

No artigo, "A leitura de livros no Primeiro Grau", publicado por Marjory Hardy na Revista de Educação, em dezembro de 1933, a autora explorou duas questões a respeito de como deveria ser o uso dos livros de leitura no primeiro grau. A primeira se refere ao tempo de liberação do livro para as crianças e outra sobre quais os procedimentos mais adequados para se realizar um trabalho pedagógico com o livro de leitura em sala de aula.

Segundo a autora, o mestre precisaria cuidar para que a leitura do livro fosse associada a algo bom e agradável, como também, ajudar o aluno a conseguir bons hábitos de leitura, porque atitudes e hábitos, segundo o autor, não podem ser ensinados, mas deveriam ser adquiridos por vontade própria, e para isso era conveniente formar uma "anatomia mental", em que a criança compreendesse o ato de ler como $o$ ato de pensar $\mathrm{e}$ não como mera associação de palavras.

Para isso as crianças deveriam ter acesso aos livros de leitura logo no início das aulas, o que provocaria uma aprendizagem mais independente. Entretanto os livros poderiam ser emprestados apenas quando a criança se manifestasse pronta para ler. A prontidão para a leitura acontecia anterior ao uso da Cartilha e mediante a aquisição de várias situações: fosse pela manifestação do interesse pelos livros, quando houvesse oportunidade de manuseá-los, de falar sobre eles e de estabelecer associações agradáveis a seu respeito; fosse pela noção de importância e prazer que a leitura poderia proporcionar; fosse pela participação em composição de grupos (narrativas de experiência) ou por vivenciar a mecânica da leitura, o movimento dos olhos da esquerda para direita e pela página abaixo; fosse, ainda, pela capacidade de se concentrar, de escutar atenta a leitura de histórias e de contá-las, novamente. Se a criança manifestasse o domínio dessas habilidades seria o momento oportuno para lhe disponibilizar os livros.

Desta forma, quando a criança apresentasse todos os aspectos que a caracterizasse pronta para a leitura e associada ao desejo agradável de lê-los, o professor poderia, então, escolher o trecho mais propício para se realizar a leitura, visto que

A escolha de material para a leitura do primeiro livro é um dever importantíssimo do professor. O melhor tipo a escolher é um que contenha histórias breves, contadas de maneira simples e natural. O menino deve ler trechos não só imaginativos senão também factíveis. O material factível é o melhor para servir de ponto-de-partida se as historias se baseiam em experiências comuns à maior parte das crianças e compreensíveis de todas. Este material é uma continuação natural do material empregado durante a fase anterior à cartilha. Os meninos fazem progressos mais rápidos de começar o livro se as histórias possuem 
continuidade de interesse. Interessam-se em acompanhar as experiências dos mesmos personagens em todo o ocorrer dos livros e esse interesse serve de estimulo que impele o menino a querer sempre estar lendo para diante, o que constitue um belo desideratum. (HARDY, 1933, p. 51)

Assim, à medida que a criança fosse adquirindo independência em sua leitura, devia-se variar o material de leitura, apresentando-lhe obras, vistas como simples, mas interessantes, pois, de acordo com Hardy (1933, p. 51), "[...] se aprende a ler lendo". A autora exemplificou como seria os procedimentos em relação ao uso das histórias nos livros:

Depois de ter a criança contado a historia uma vez com o auxilio do professor,
deve em algum período separado, obter mais auxilio antes de tornar a ler a
historia. Deve ter uma oportunidade nesta ocasião para ver grupos de palavras
separadas da historia e impressos em cartões. Dá-se-lhe então um ensejo para
reunir os grupos de palavras e as palavras isoladas em porta-cartão de estampas
de maneira tal que as palavras possam ser vistas em uma combinação
significativa. O professor pode reunir os cartões de modo que formem sentenças
da historia. Convém dar aos meninos uma oportunidade para arranjarem as
sentenças fazendo assim o menino tornar-se côncio das palavras de maneira
natural e sem perder o conteúdo da história.
No seguinte período de leitura pode-se tornar a ler a historia, proporcionando ao
menino uma oportunidade para ligar palavras com a história depois de recebido
preparo para assim fazer com cartões. Entretanto, nessa ocasião não convém
mencionar especialmente formas de palavras, pois quando o menino está retendo
no espírito o conteúdo, as formas de palavras ou a mecânica fazem solução de
continuidade no seu pensamento.
Quando o menino le no livro deve-se tratar de conserva-lo no ambiente da historia
por meio de comentários do professor sobre o conteúdo dela. Quando o menino le
algumas das primeiras historias no livro, este auxilio vira por meio de instruções
[...].

O livro de leitura adquiria um determinado ritual de uso, concretizado pelas atitudes e iniciativas do professor. Com isso, o docente assumia um papel de intensa responsabilidade, não apenas no ensino e aprendizagem da leitura - procedimentos mecânicos, de decodificação - como também no desenvolvimento de uma habilidade leitora, ou seja, despertando-Ihe um gosto e um modo de uso da capacidade mental.

Era o professor quem escolheria a leitura, direcionaria e orientaria as possíveis formas de realizá-la, como também a ele caberia a continuidade desse processo, criando questões a respeito da história. A ele competia, ainda, a ajuda e o preparo do aluno "[...] guiando para a meta conveniente e tornando possível que o discípulo aprecie cada passo do caminho" (HARDY, 1933, p. 51).

Na Escola Secundária, que tinha como função preparar o aluno para o ingresso na Universidade, ao livro de texto foi atribuída uma ideia de complementação do trabalho pedagógico, um material que ministrava o conteúdo de forma condensada. Segundo Calvo (1933, p. 387), a utilização da obra didática requeria alguns cuidados, pois o apego servil ao livro de texto seria incoerente e prejudicial, visto que "o texto deve ser um esboço da extensão do trabalho, deve marcar limites a atingir".

Para evitar possíveis contrassensos, ao utilizar os livros o professor necessitaria saber identificá-los. Assim, Calvo (1933, p. 387), como outros autores, prescreveu uma classificação para os livros didáticos. Para ele, havia dois tipos de livros de texto: 0 "informativo" e o "pedagógico". O primeiro referia-se a um conjunto de doutrinas, enquanto 
o outro ordenava os conhecimentos e dispunha-o em partes para melhor ensiná-los. A preferência para uso, em sala, deveria ocorrer para os livros do "tipo pedagógico" e não para os "informativos", por serem considerados como um "guia metodológico" para o professor.

Para o autor, o trabalho com o "livro de texto" se concretizava a partir da aplicação de duas metodologias de aprendizagem, uma exigida pela "leitura inteligente", que consistia na realização de uma leitura rápida do texto, com o propósito de descobrir a ideia central do autor. A outra requereria pela aplicação de uma "leitura para recordar", que consistia numa atividade de leitura como ato de revisão, cujo objetivo era recuperar os temas ou conteúdos já trabalhados.

Outro cuidado, na utilização do material, deveria estar para além da "[...] natureza intrínseca do livro", isto é "[...] não devem ser olvidas as suas condições materiaes (apresentação typográfica, gravuras, eschemas, quadros synopticos, índices, etc.)" (CALVO, 1934, p. 387).

A leitura se restringiria aos textos contidos nos livros, outros escritos demarcados por protocolos de leitura ou dispositivos gráficos e textuais, deveriam ser desprezados, um discurso que, supostamente, se mostrava guiado por uma ideia de que tais informações retardariam ou dispersariam o leitor da verdadeira essência dos conteúdos ou da temática em discussão.

Ainda explorando a questão metodológica, o professor poderia, de acordo com este autor, realizar um "bom" e um "mau" uso do livro de texto. O "mau" uso consistia em demarcar lições para serem realizadas sem uma prévia explicação ou orientação. Já o "bom" uso fundamentava-se pelo seguimento e pela aplicação de vários passos, entre eles, por exemplo, dever-se-ia considerar o livro de texto como guia para trabalhos experimentais ou investigações; propor questões, cujas respostas exigem-se a consulta no texto ou consulta aos assuntos mais importantes do livro; dosar a quantidade de tarefas diárias; realizar a leitura e a interpretação seguida de perguntas; usar o texto para grupos de estudo, para aplicação de provas e de exercícios de revisão, entre outras.

Como já anteriormente ocorrido, as opiniões sobre o livro didático e seus modos de uso, não caminhavam em linhas contínuas de ideias, mas em linhas marcadas por diversas opiniões que divergiam pela descontinuidade. E em relação à ideia do que seria um "bom" uso do livro de texto, não seria diferente, nem mesmo em relação ao entendimento das formas de procedência diante da "natureza do livro" (entendida como a constituição física, sua estruturação e disposição do escrito). Adams (1933, p. 60), por exemplo, defendia que o uso correto das diversas partes do livro consistia no

Uso eficiente do sumário, do índice, do apêndice, do vocabulário de pronuncia figurada e do glossário, e das notas. Embora seja uma economia de tempo durante a aula indicar a página da lição e fornecer aos alunos certas informações de preferência a fazê-los procurar tais informações por si, se se empregar sempre este sistema, esta prática resultará em uma atitude de dependência da parte do aluno. A professora deve em certas ocasiões dar instruções especiais no uso das diferentes partes do livro, desenvolvendo para cada uma das partes destinadas a prestar auxílio ao leitor no uso do livro. Convém que os alunos consultem com frequência, sob cuidadosa direção, os índices dos compêndios de geografia, história, aritmética e leitura. Convém também incumbir nos alunos de examinarem abreviadamente livros novos para eles e darem na classe um relatório da natureza do livro e do seu conteúdo. (ADAMS, 1933, p. 60) 
Enquanto os discursos destes autores assinalavam a qualidade da obra a partir dos elementos gráficos ou temáticos que deveriam, ou não, predominar em sua elaboração e, principalmente, no uso destes recursos dispostos no livro de leitura, no decorrer desta década outras publicações apontariam que a qualidade dos livros estaria distante de ser atingida.

\section{Considerações finais}

Ao analisar diferentes discursos publicados entre as primeiras décadas do século $\mathrm{XX}$, este trabalho assumiu como objetivo compreender o que tais escritos traziam como marcas de uma representatividade, a respeito do que se entendia por "bom" uso do livro de leitura, e quais ideias envolviam as questões direcionadas à utilização e à apropriação das obras nas escolas públicas paulistas.

Ao apresentar diferentes discursos sobre o uso dos livros nas escolas entende-se que a palavra escrita se torna um "fenômeno ideológico por excelência", conforme aponta Bakhtin (2006), e a aproximação de tais enunciados permite uma ideia do que se compreendia por livro de leitura em determinados períodos da história da educação brasileira.

Para isso, este artigo destacou que o processo de adesão ao livro escolar aparece marcado por questões políticas, sociais e culturais. Os discursos circulam reafirmando uma ideia do livro de leitura como um instrumento básico para o trabalho do professor. O que ocorria, de fato, era um aumento significativo da presença dos livros de leitura nas escolas públicas. Isso gerou uma produção de discursos que traziam preocupações com o modo de organização do trabalho pedagógico, com a definição de livro de leitura e com os modos de organização e uso da obra didática.

O livro de leitura é considerado um objeto desencadeador de uma cultura material escolar, por configurar-se a partir de um espaço concreto, ou seja, de uma materialidade em que é possível visualizar, juntamente ao conteúdo escrito, uma temporalidade, marcas de um momento da histórico e social da educação, com suas preocupações ideológicas e metodológicas, moldados por um discurso carregado de uma intencionalidade de orientar e determinar o trabalho docente em relação aos modos de uso do livro de leitura, acenados por uma linguagem escrita que seleciona textos, prescreve atividades e articula ações leitoras.

Os discursos que ora buscam uma definição para o livro de leitura como um auxiliar para o ensino, ora determinam modos de uso da obra, atribuindo um julgamento valorativo das ações pedagógicas em "bom" e em "mau" uso do livro de texto, ou das ações leitoras como "leitura inteligente" ou "leitura para recordar", sinalizam uma preocupação direcionada para as formas de relação entre o professor e o livro para conduzir o leitor-aluno nas atividades de leitura com e sobre o livro, especificamente no ambiente escolar.

As reflexões desenvolvidas a partir de diferentes textos, produzidos num período de quase vinte anos, permitem considerar o livro de leitura como símbolo "cultura material escrita", por se configurar em sua materialidade, de acordo com Bittencourt (1993), as produções discursivas de aperfeiçoamento técnico da produção de obras didáticas; pelo acesso e a viabilidade de compra das obras e pela ideia de formação do corpo docente, 
do livro como complementariedade do trabalho pedagógico.

\section{Referências}

ANTUNHA, Heladio Cesar Gonçalves. A reforma de 1920 da instrução pública no estado de São Paulo. 1967. 379 f. Tese (Doutorado) - Faculdade de Filosofia, Ciências e Letras, Universidade de São Paulo, São Paulo, 1967.

BAKHTIN, M. Marxismo e filosofia da linguagem. São Paulo: Hucitec, 2006. 2003.

. Estética da criação verbal. $4^{a}$ ed. Trad. Paulo Bezerra. São Paulo: Martins Fontes,

BITTENCOURT, Circe Maria Fernandes. Livro didático e conhecimento histórico: uma história do saber escolar. 369 f.1993. Tese (Doutorado em História Social) - Faculdade de Filosofia, Letras e Ciências Humanas, Universidade de São Paulo, São Paulo,1993.

CAVALIERE, Ana Maria. Entre o pioneirismo e o impasse: a reforma paulista de 1920. Revista Educação e Pesquisa, São Paulo, v. 29, n. 1, p. 27-44, jan./jun. 2003.

CHARTIER, Roger (Org.). A história ou a leitura do tempo. Belo Horizonte: Autêntica, 2009.

História Cultural: entre práticas e representações. Trad. M. M. Galhardo. Lisboa: Difel; Rio de Janeiro: Bertrand Brasil, 2002.

A aventura do livro: do leitor ao navegador. Trad. Reginaldo de Moraes. São Paulo: UNESP, 1999.

. Práticas da leitura. São Paulo: Estação da Liberdade, 1996.

A ordem dos livros: leitores, autores e bibliotecas na Europa entre os séculos XIV e XVIII. Trad. M. Del Priore. Brasília: Ed. UnB, 1994.

VIDAL, Diana Gonçalves. No interior da sala de aula: ensaio sobre cultura e prática escolares. Currículo sem fronteiras, v. 9, n. 1, p. 25-41, 2009.

Nacionalismo e tradição na prática discursiva de Fernando de Azevedo. Revista Instituto de Estudos Brasileiros, São Paulo, n. 37, p. 35-51, 1994.

VIDAL, Diana Gonçalves; FARIA FILHO, Luciano Mendes. As lentes da história: estudos de história e historiografia da educação no Brasil. Campinas: Autores Associados, 2005.

\section{Documentos analisados}

ADAMS, Mary A. A leitura nos graus intermediários. Revista de Educação, Orgão da Diretoria Geral do Ensino do Estado de São Paulo, São Paulo, v. IV, p. 57-61, dezembro 1933.

AZEVEDO, Fernando de. O Livro e a Escola Nova. Revista de Educação, Secção: Atraves de Revistas, v. IV, dezembro 1933.

CALVO, José. O livro de texto. Revista Educação, São Paulo, Seção Através de Revistas, v. III, dezembro 1934.

CAMPOS, Maria dos Reis. Escola Moderna - conceitos e práticas. 3. ed. São Paulo: Francisco Alves, 1946.

DEPARTAMENTO DE EDUCAÇÃO. Programa de Linguagem. Directoria Geral de Instrucção Pública. Rio de Janeiro. Série C. Programas. n. 1, 1934.

HARDY, Marjory. A leitura de livros no Primeiro Grau. Revista de Educação, São Paulo, v. 
IV, dezembro 1933.

REVISTA Escolar. Orgam da Directoria Geral da Instrucção Publica, São Paulo, anno III, n. 28. São Paulo, abril 1927.

WHITE, Emerson E. Preparação do mestre: o mestre - uso do livro de leitura. Revista Escolar. São Paulo: Orgam da Directoria Geral da Instrucção Pública, São Paulo, ano III, n. 27, p. 3-6, março 1927.

ILSA DO CARMO VIEIRA GOULART é professora do Departamento de Educação da Universidade Federal de Lavras, Doutora em Educação pela Universidade Estadual de Campinas e coordenadora do Núcleo de Estudos em Linguagens, Leitura e Escrita - Nelle. Endereço: Universidade Federal de Lavras - Campus Universitário - Caixa Postal 3037 37200-000 - Lavras/MG - Brasil.

E-mail: ilsa.goulart@ded.ufla.br

Recebido em 01 de maio de 2015.

Aceito em 04 de novembro de 2016. 